BASIC RESEARCH

\title{
Angiotensin converting enzyme inhibitor prevents left ventricular remodelling after myocardial infarction in angiotensin II type 1 receptor knockout mice
}

\author{
M Yoshiyama, Y Nakamura, T Omura, Y Izumi, R Matsumoto, S Oda, K Takeuchi, S Kim, H Iwao, \\ J Yoshikawa
}

Heart 2005;91:1080-1085. doi: 10.1136/hrt.2004.035618

See end of article for authors' affiliations

Correspondence to:

Dr Minoru Yoshiyama,

Department of Internal

Medicine and Cardiology,

Graduate School of

Medicine, Osaka City

University, 1-4-3, Asahi-

machi, Abeno-ku, Osaka

545-8585, Japan;

yoshiyama@

med.osaka-cu.ac.jp

Accepted 7 July 2004

\begin{abstract}
Background: It is well known that angiotensin converting enzyme (ACE) inhibitors and angiotensin II type 1 (AT1) receptor blockers (ARBs) prevent left ventricular (LV) remodelling after myocardial infarction (MI). However, it is still not clear whether inhibition of the ATI receptor is enough to prevent LV remodelling after MI.

Objective: To elucidate the effects of ACE inhibitors that are not mediated by the ATI receptor on LV remodelling, MI was experimentally induced in wild-type (WT-MI) mice and AT1 receptor knockout (KOMI) mice.

Methods: Mice were divided into six groups: WT-control, KO-control, WT-MI, KO-MI, WT-MI treated with an ACE inhibitor, and KO-MI treated with an ACE inhibitor. Four weeks after $\mathrm{Ml}$, cardiac function was assessed by Doppler echocardiography and non-infarcted myocardial mRNA expression by northern blot analysis.

Results: Cardiac function decreased significantly in the Ml groups compared with the sham operated groups. Additionally, in the Ml groups end diastolic dimension, E wave velocity, the ratio of peak velocity of $E$ wave to $A$ wave, deceleration rate of $E$ wave, and mRNA expression of atrial natriuretic peptide, brain natriuretic peptide, and collagens I and III increased significantly compared with the sham groups. LV remodelling after MI was prevented in KO-MI mice compared with WT-MI mice. ACE inhibitor administration significantly attenuated progressive LV remodelling in both WT and KO-MI groups.

Conclusion: ACE inhibitors can prevent the LV remodelling process that accompanies cardiac dysfunction after MI, even in ATI KO mice. These findings suggest that ACE inhibitors prevent LV remodelling after $\mathrm{Ml}$ by mechanisms other than inhibition of angiotensin AT1 receptor mediated effects.
\end{abstract}

A ccumulating evidence supports the proposal that angiotensin II type 1 (ATl) receptor blockers (ARBs) have nearly the same beneficial effects as angiotensin converting enzyme (ACE) inhibitors on cardiac hypertrophy, remodelling, and heart failure. ${ }^{1-3}$ However, the pharmacological profiles of ARBs and ACE inhibitors differ substantially. ARBs can inhibit the action of angiotensin II generated through not only ACE but also alternative pathways, whereas ACE inhibitors block the breakdown of bradykinin. ${ }^{56}$ Therefore, combination treatment with an ACE inhibitor and ARB may offer benefits greater than the benefits of either agent used alone. In the Val-HeFT (valsartan heart failure trial) $^{7}$ and CHARM (candesartan in heart failure-assessment of reduction in mortality and morbidity) studies, ${ }^{8}$ combination treatment with an ACE inhibitor and an ARB provided enhanced benefits in heart failure. Recently, we showed that combined administration of an ACE inhibitor and an ARB prevents left ventricular (LV) remodelling after myocardial infarction (MI) in rats more effectively than either drug administered on its own. ${ }^{9}$ Valsartan is as effective as captopril in patients at high risk for cardiovascular events after MI; however, combining valsartan with captopril does not improve survival. ${ }^{10}$

We hypothesised that ACE inhibitors may prevent LV remodelling after MI despite the lack of expression of the ATI receptor. In the present study, we experimentally induced MI in wild-type (WT-MI) mice and ATl receptor knockout (KOMI) mice that were either treated or not treated with an ACE inhibitor. At four weeks after MI, we assessed cardiac function by Doppler echocardiography and cardiac gene expression to ascertain whether ACE inhibitors can prevent LV remodelling after MI without ATl receptor inhibition.

\section{METHODS}

\section{Induction of MI}

KO mice and WT mice (all 16 week old C57BL/6 of the same genetic background, weighing 29-31 g) were used in the present study. ${ }^{11}$ An MI was induced according to a previously described method. ${ }^{12}{ }^{13}$ Mice were anaesthetised with pentobarbital sodium (35 mg/kg intraperitoneally) and lidocaine hydrochloride $(10 \mathrm{mg} / \mathrm{kg}$ intraperitoneally). After tracheal intubation, the mice were artificially ventilated with a small animal respirator. MI was induced by permanently ligating the left coronary artery with a 9-0 nylon surgical suture under a dissection microscope. The same surgical procedures were also performed in sham operated mice, except for the coronary ligation.

The mice were separated into six groups (7-10 mice in each group): sham operated WT mice (WT-controls); sham operated KO mice (KO-controls); WT-MI mice; KO-MI mice; WT-MI mice treated with an ACE inhibitor (imidapril

Abbreviations: $A C E$, angiotensin converting enzyme; $A N P$, atrial natriuretic peptide; ARB, angiotensin II type 1 receptor blocker; $A T 1$, angiotensin II type 1; BNP, brain natriuretic peptide; CHARM candesartan in heart failure-assessment of reduction in mortality and morbidity; \%FS, percentage of fractional shortening; $\mathrm{KO}$, knockout; LV, left ventricular; MI, myocardial infarction; RV, right ventricular; Val-HefT, valsartan heart failure trial; WT, wild type 
$10 \mathrm{mg} / \mathrm{kg} /$ day); and KO-MI mice treated with an ACE inhibitor (imidapril $10 \mathrm{mg} / \mathrm{kg} /$ day). Immediately after coronary ligation, imidapril was administered in drinking water based on the observed average water consumption of mice. Four weeks after MI, the heart rate and systolic blood pressure of conscious mice were measured by the tail cuff method, echocardiography was performed, and after the animals were killed the ventricles were excised. Infarct size was calculated and expressed as a percentage of LV surface area as previously described..$^{14}$ Mice with an infarct size $<20 \%$ were excluded from analysis.

\section{Echocardiographic studies}

Mice were lightly anaesthetised with ketamine hydrochloride $(25 \mathrm{mg} / \mathrm{kg}$ intraperitoneally) and xylazine $(10 \mathrm{mg} / \mathrm{kg}$ intraperitoneally). Echocardiography was performed with a commercially available echocardiographic system equipped with a $12 \mathrm{MHz}$ phased array transducer (SONOS 5500, Phillips, Andover, Massachusetts, USA). A two dimensional short axis view of the LV was obtained at the level of the papillary muscles. Pulsed wave Doppler spectra of mitral inflow velocities were recorded from the apical four chamber view, with the sample volume placed near the tips of the mitral leaflets and adjusted to the position at which velocity was maximum and the flow pattern was laminar. The sample volume was set at the smallest size available. All Doppler spectra were recorded at a paper speed of $200 \mathrm{~mm} / \mathrm{s}$ and analysed off line.

RNA preparation and northern blot hybridisation

All procedures were performed as previously described..$^{15}$ In brief, total RNA was isolated from the individual noninfarcted LV and right ventricle by the guanidium thiocyanate-phenol-chloroform method and $20 \mathrm{mg}$ of total RNA was subjected to $1 \%$ agarose gel electrophoresis and transferred to a nylon membrane. Hybridisation was carried out with a $\left({ }^{32} \mathrm{P}\right)$-dCTP labelled cDNA probe for atrial natriuretic peptide (ANP), brain natriuretic peptide (BNP), collagen type I, collagen type III, or glyceraldehyde-3-phosphate dehydrogenase. The density of an individual mRNA band was measured with a bioimaging analyser (BAS-2000, Fuji Photo Film Co, Tokyo, Japan).

\section{Statistical analysis}

All results are expressed as mean (SEM). Significance was determined by analysis of variance. Differences were considered significant at $\mathrm{p}<0.05$.

\section{RESULTS}

\section{Anatomical pathology}

Figure 1 shows the heart shapes from the six groups. WT-MI and KO-MI (MI groups) hearts were enlarged compared with WT-controls or KO-controls; the enlargement in KO-MI mice was less than in WT-MI mice. ACE inhibitor treatment significantly attenuated the enlargement in MI even in the KO mice model. Figure 2 shows transverse LV sections stained by azan from the six groups taken from the apical view. The LV cavities in WT-MI and KO-MI mice were dilated. LV cavity dilatation in KO-MI mice was less than in WT-MI mice. ACE inhibitor treatment significantly attenuated dilatation of the LV cavity in MI, even in the KO model.

\section{Haemodynamic data and ventricular weights}

Table 1 shows the haemodynamic data and ventricular weights in the six groups. Blood pressure was significantly lower in KO-controls than in WT-controls $(p<0.01)$. In KOMI mice, blood pressure was significantly lower than in WTMI mice $(p<0.01)$. Although ACE inhibitor treatment significantly decreased blood pressure in WT-MI mice $(\mathrm{p}<0.05)$, a trend towards decreased blood pressure in KO-MI mice was also observed. LV and right ventricular (RV) weights, corrected for body weight, in the MI groups were significantly greater than in the corresponding control groups. ACE inhibitor treatment significantly reduced the LV and RV weights in WT-MI mice and tended to reduce the LV and RV weights in KO-MI mice. Infarct size was similar in all groups.

\section{MI}

Control
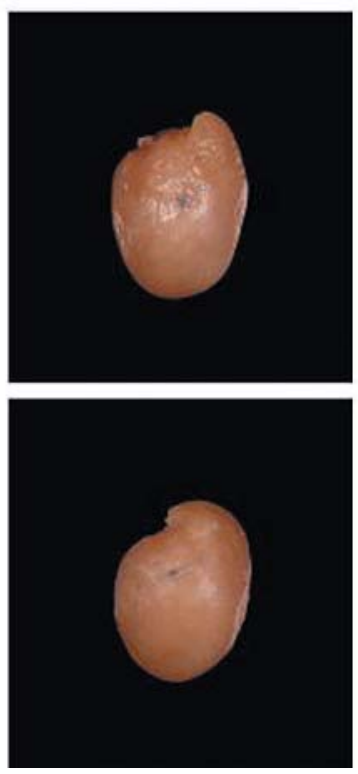

ACEI (-)
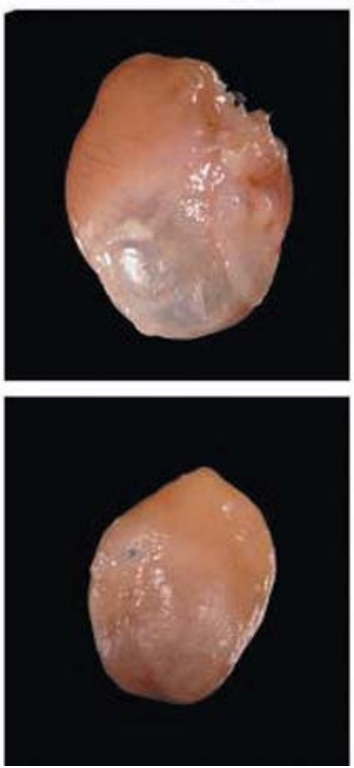

Figure 1 Anatomical pathology from a wild-type (WT) control mouse, a knockout (KO) control mouse, a WT mouse with experimentally induced myocardial infarction (MI), and a $\mathrm{KO}$ $\mathrm{Ml}$ mouse. Angiotensin converting enzyme inhibitor (ACEI) was administered to WT-Ml and KO-MI mice. WT-MI and KO-MI mice had enlarged hearts compared with WTcontrol mice or KO-control mice. ACEI prevented this enlargement.
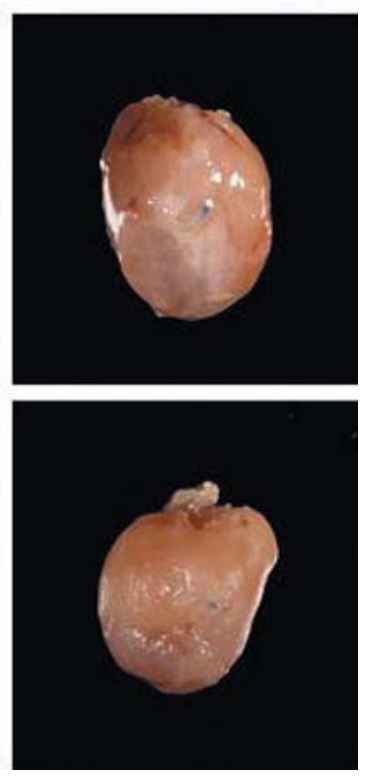


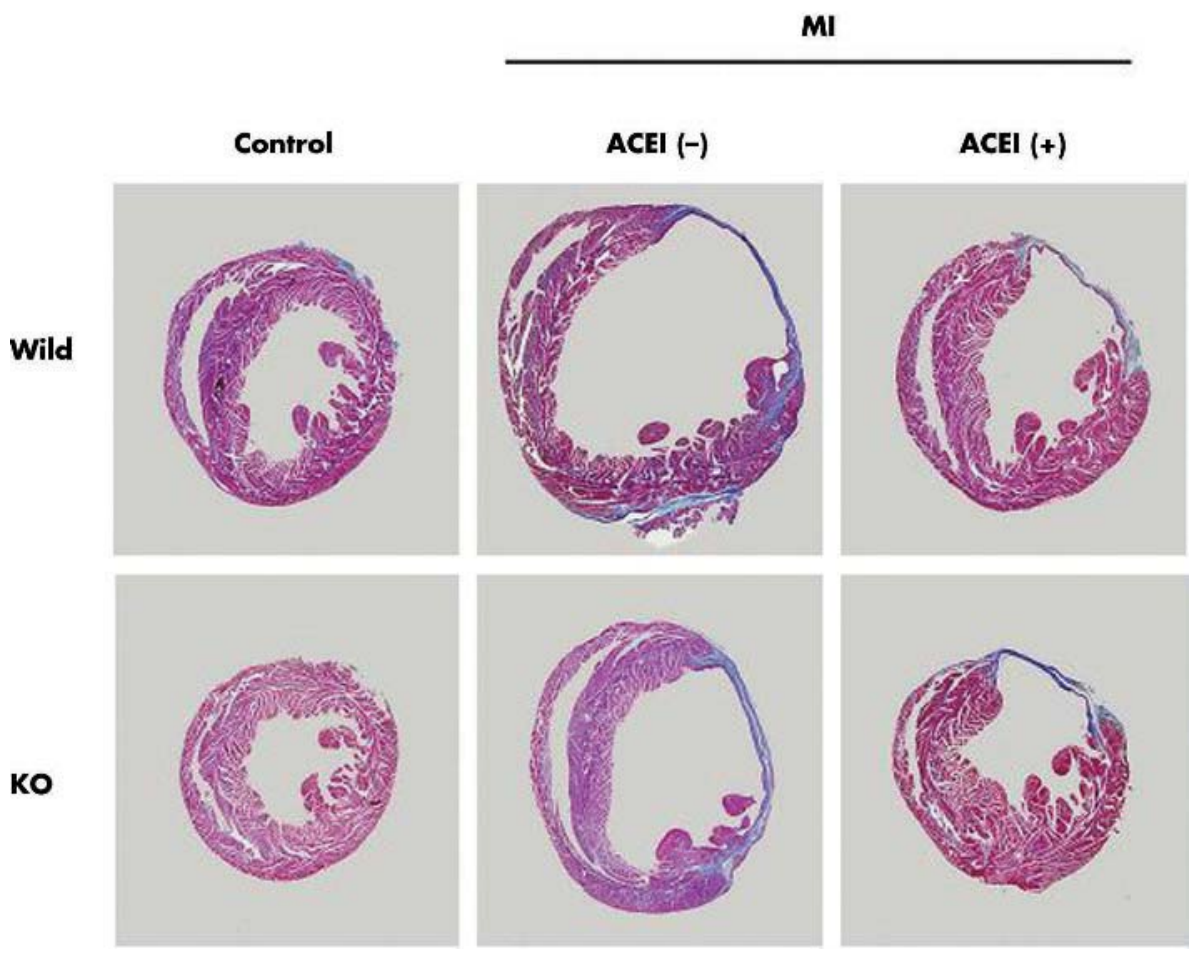

Figure 2 Azan stains of transverse left ventricular (LV) sections (mid cavity) from a WT-control mouse, a KO-control mouse, a WT-MI mouse, a KO-MI mouse, a WT-MI mouse treated with ACEl, and a KO-MI mouse treated with ACEI. The LV cavities in WT-MI and KO-MI mice were dilated. ACEI prevented dilatation in LV cavities in WT-MI mice and KO-MI mice.

\section{Doppler echocardiographic assessments of LV geometry and function}

Figure 3 shows representative echocardiographic short axis images taken during the internal diastolic phase. Table 2 shows the echocardiographic assessments. The LV diastolic dimension in the MI groups was significantly larger than in the control groups. Moreover, ACE inhibitor significantly reduced diastolic dimension in the corresponding MI groups, even in the KO model. The MI groups had significant systolic dysfunction, as shown by the percentage of fractional shortening $(\% \mathrm{FS})$. The $\% \mathrm{FS}$ in $\mathrm{KO}-\mathrm{MI}$ mice was significantly higher than in WT-MI mice. Moreover, ACE inhibitor treatment significantly improved the \%FS in the corresponding MI groups, even in the $\mathrm{KO}$ model. The ratio of $\mathrm{E}$ wave peak velocity to A wave peak velocity in the MI groups was much higher than in the control groups (fig 4). The ratio in KO-MI mice was significantly lower than in WT-MI mice $(\mathrm{p}<0.01)$. However, ACE inhibitors did not significantly further lower the ratio in the corresponding MI groups, even in the KO model.

\section{Cardiac gene expression of ANP, BNP, and collagen types I and III}

Table 3 and fig 5 show the results of cardiac gene expression determination in the six groups. mRNA expression of ANP, BNP, and collagen types I and III by the non-infarcted myocardium was significantly increased in the MI groups compared with the control groups. mRNA expression in noninfarcted myocardium was significantly decreased in KO-MI mice compared with WT-MI mice. Moreover, ACE inhibitor significantly decreased mRNA expression in the corresponding MI groups, even in the KO model.

\section{DISCUSSION}

Chronic heart failure may develop after MI, which causes LV dilatation and adaptive responses in both infarcted and noninfarcted regions of the heart. ${ }^{16}{ }^{17}$ These changes, called postMI remodelling, ${ }^{18}$ may contribute to LV systolic and diastolic dysfunction after MI. Previous studies have suggested that the cardiac renin-angiotensin system is activated during this remodelling process. ${ }^{19} 20$ In addition, many studies have

Table 1 Haemodynamic data and ventricular weights in control mice and mice with experimentally induced MI

\begin{tabular}{|c|c|c|c|c|c|c|}
\hline & \multirow{2}{*}{$\begin{array}{l}\text { WT-control: } \\
\text { ACEI (-) }\end{array}$} & \multirow{2}{*}{$\begin{array}{l}\text { KO-control: } \\
\text { ACEI (-) }\end{array}$} & \multicolumn{2}{|l|}{ WT-MI } & \multicolumn{2}{|l|}{ KO-MI } \\
\hline & & & ACEI (-) & ACEI (+) & ACEI (-) & ACEI (+) \\
\hline HR (beats/min) & $662(29)$ & $627(24)$ & $545(24)$ & $600(29)$ & $537(42)$ & $583(25)$ \\
\hline Mean $\mathrm{BP}(\mathrm{mm} \mathrm{Hg})$ & $137(4)$ & $117(6)^{* *}$ & $105(5)^{\star \star}$ & $94(2)^{\star *} \dagger$ & 90 (5)††㧊 & $86(2) \ddagger \ddagger$ \\
\hline $\mathrm{LV} / \mathrm{BW}(\mathrm{g} / \mathrm{kg})$ & $3.01(0.14)$ & $2.98(0.15)$ & $3.97(0.16)^{\text {** }}$ & $3.29(0.11)+\dagger$ & $3.57(0.23) \ddagger$ & $3.29(0.11)$ \\
\hline $\mathrm{RV} / \mathrm{BW}(\mathrm{g} / \mathrm{kg})$ & $0.74(0.08)$ & $0.69(0.06)$ & $1.19(0.09)^{* *}$ & $0.90(0.08) \dagger$ & $0.94(0.09) \ddagger$ & $0.85(0.08)$ \\
\hline MI size $(\%)$ & NA & NA & $36(3)$ & $35(4)$ & $35(2)$ & $33(4)$ \\
\hline
\end{tabular}

Values are mean (SEM)

$\mathrm{ACEl}$, angiotensin converting enzyme inhibitor; BP; blood pressure, BW, body weight; $\mathrm{KO}$, knockout type; LV, left ventricular weight; MI, myocardial infarction; NA, not applicable; RV, right ventricular weight; WT, wild type.

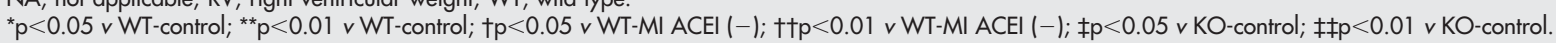




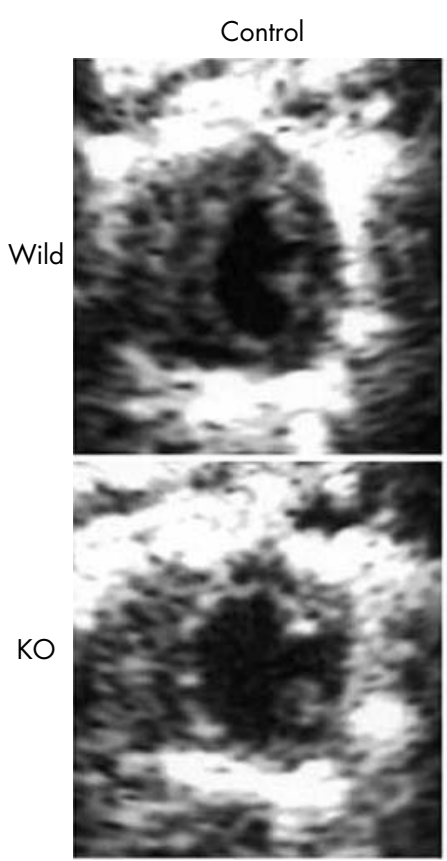

$M$

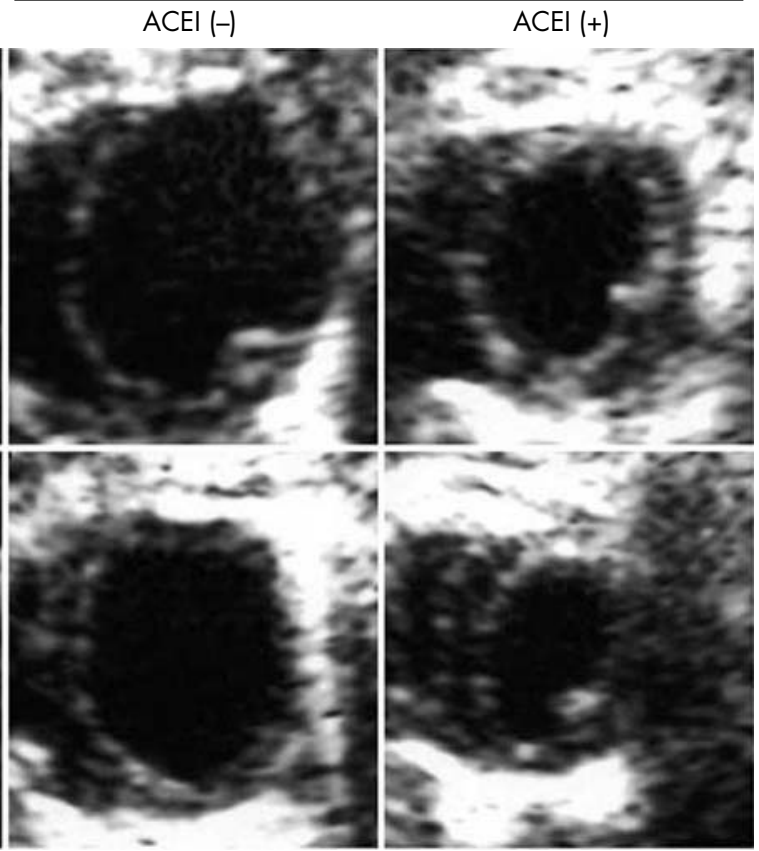

Figure 3 Examples of two dimensional echocardiograms (parasternal short axis view) from a WT-control mouse, a $\mathrm{KO}$-control mouse, a WT-MI mouse, a KO-MI mouse, a WT-MI mouse treated with $\mathrm{ACEl}$, and a $\mathrm{KO}-\mathrm{Ml}$ mouse treated with ACEl. Short axis images were obtained at the level of the papillary muscles for consistency. Note the prominent increase in LV diastolic dimension in the mouse with the MI. ACEl decreased LV diastolic dimensions in WT-MI and KO-MI mice. shown that inhibition of the cardiac renin-angiotensin system prevents geometric remodelling and LV dysfunction after MI. ${ }^{18}$ Experimental evidence indicates that the influence of ACE inhibitor treatment on LV remodelling after MI may involve both direct angiotensin II effects acting through a variety of angiotensin II receptor subtypes and indirect effects on the kallikrein-kinin system. ${ }^{521}$ The observations made in this study suggest that ACE inhibitor treatment has a beneficial effect on cardiac remodelling without inhibiting angiotensin II effects through the ATI receptor.

As indicated by echocardiography, mice with experimentally induced MI had significant systolic and diastolic dysfunction as shown by the major decrease of \%FS and the increase in E:A. In this study, it was found that ACE inhibition significantly improved cardiac dysfunction in MI mice. Doppler echocardiography is the primary technique for evaluating LV diastolic function. ${ }^{22}$ Increased E wave velocity, decreased peak A wave velocity (or absent A wave), and rapid E wave deceleration were observed in the mice, and these flow patterns were similar to transmitral flow profiles observed in patients with heart failure with a restrictive pattern. ACE inhibitor prevented increased collagen I and III mRNA concentrations, indicating that ACE inhibitors may prevent cardiac fibrosis. Continued cardiac load that is insufficient to normalise increased wall tension activates the expression of ANP and BNP. ${ }^{23}$ ANP and BNP concentrations are markers of the degree of LV dysfunction and LV remodelling in $\mathrm{MI}^{24}$ In the present study, ANP and BNP mRNA concentrations were significantly suppressed in $\mathrm{KO}$ MI mice treated with an ACE inhibitor compared with the KO-MI mice. We suggest that the ACE inhibitor, which has a non-ATl receptor mediated mechanism, improved myocardial function.

ACE inhibitors are known to increase tissue bradykinin accumulation. Bradykinin has antigrowth effects and reduces vasomotor tone. Increased kinin activation resulting from ACE inhibition may attenuate structural remodelling in the infarcted heart. Some studies have previously reported that ACE inhibitors attenuated the deterioration of LV function and remodelling in animals with chronic heart failure caused by MI. ${ }^{16}$ This effect was either blocked by a B2 kinin receptor antagonist ${ }^{25} 26$ or blunted in rats with kininogen deficiency due to spontaneous mutation of the kininogen gene, ${ }^{27}$ indicating that kinins are important in the cardioprotective mechanism of ACE inhibitors. The mechanism explaining the potential antiremodelling action of bradykinin may relate to

Table 2 Doppler echocardiographic measurements in control mice and MI mice

\begin{tabular}{|c|c|c|c|c|c|c|}
\hline & \multirow{2}{*}{$\begin{array}{l}\text { WT-control: } \\
\text { ACEI (-) }\end{array}$} & \multirow{2}{*}{$\begin{array}{l}\text { KO-control: } \\
\text { ACEI (-) }\end{array}$} & \multicolumn{2}{|l|}{ WT-MI } & \multicolumn{2}{|l|}{ KO-MI } \\
\hline & & & ACEI (-) & ACEI (+) & ACEI (-) & ACEI (+) \\
\hline LVEDD (mm) & $3.6(0.1)$ & $3.8(0.1)$ & $5.2(0.2)^{* *}$ & $4.5(0.1)^{* *}+\dagger$ & 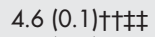 & $4.0(0.1) \S \S \oplus$ \\
\hline LVESD (mm) & 2.910 .20 & $3.0(0.2)$ & $4.8(0.2)^{* *}$ & $3.8(0.2)^{* *} \dagger \dagger$ & 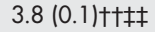 & $3.4(0.2) \S \uparrow$ \\
\hline$\% \mathrm{FS}$ & $32(3)$ & $28(3)$ & $10(2)^{* *}$ & $16(2)^{* *} \dagger$ & 15 (1)十只 & $20(1) \neq \ddagger \S \S \uparrow$ \\
\hline E wave $(\mathrm{cm} / \mathrm{s})$ & 41 (4) & $46(4)$ & $84(3)^{\star *}$ & $58(3)^{* *}+\dagger$ & 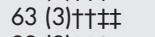 & 42 (3)§§ળ \\
\hline A wave $(\mathrm{cm} / \mathrm{s})$ & 34 (3) & 32 (4) & $11(2)^{\star *}$ & $26(2)^{*}+\dagger$ & $23(2) \dagger † \ddagger$ & $24(2) \ddagger$ \\
\hline$E: A$ & $1.7(0.2)$ & $1.8(0.2)$ & $7.8(1.2)^{\star *}$ & $3.4(0.4) \mathrm{t}+$ & $3.6(0.3) \dagger † \neq \ddagger$ & $2.5(0.4)$ \\
\hline $\mathrm{DR}\left(\mathrm{cm} / \mathrm{s}^{2}\right)$ & $877(77)$ & $922(65)$ & $1675(109)^{* *}$ & $1356(53)^{* *} \dagger$ & $1326(59) \dagger \ddagger$ & 989 (44)§ণ \\
\hline
\end{tabular}

Values are mean (SEM)

$\mathrm{DR}$, deceleration rate; \%FS, percentage of fractional shortening; LVEDD, left ventricular end diastolic dimension; LVESD, left ventricular end systolic dimension.

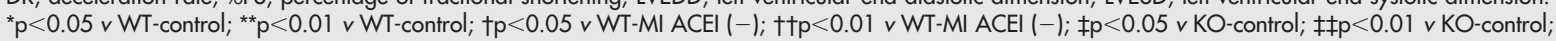
$\S p<0.05 \vee$ WT-MI ACEI (+); $\S \S p<0.01 \vee$ WT-MI ACEI $(+)$; $\uparrow p<0.05 \vee$ WT-KO ACEI $(-)$; $\uparrow p<0.01 \vee$ KO-MI ACEI (-). 
MI

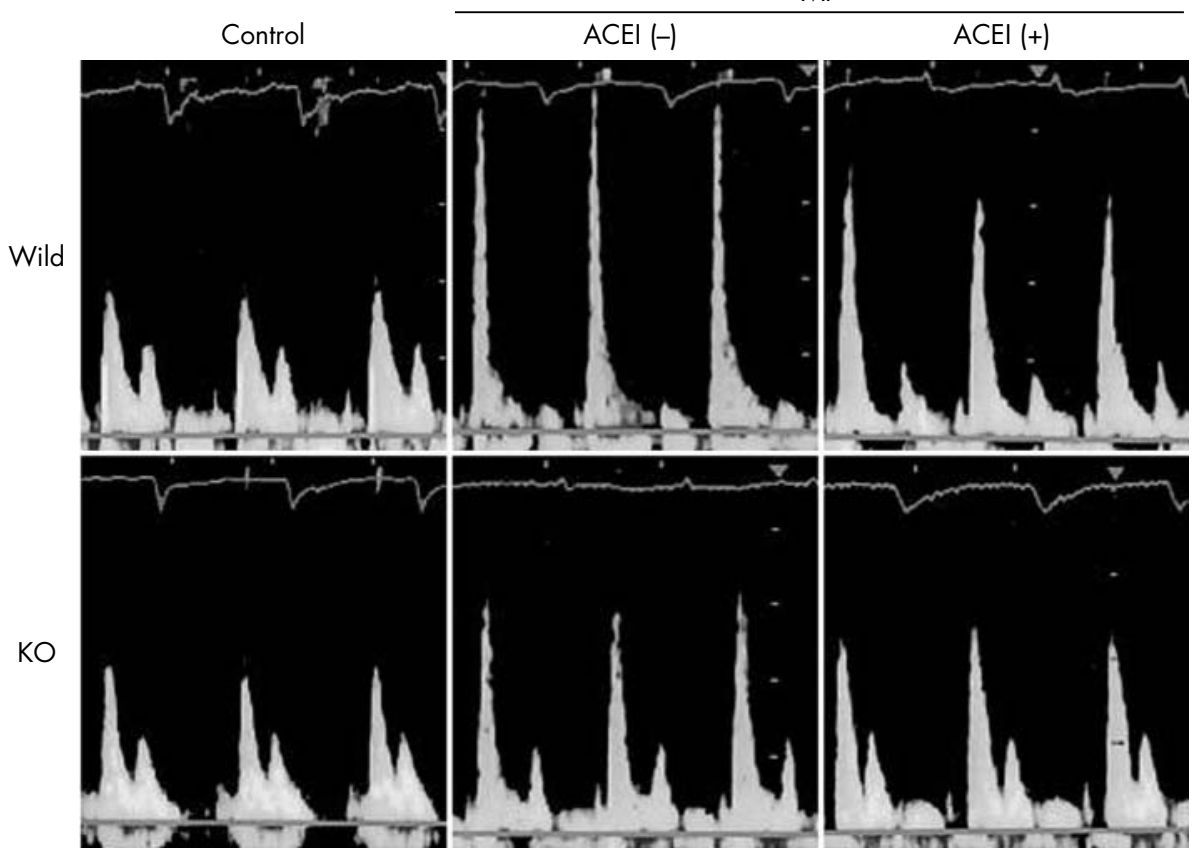

Figure 4 Examples of pulse wave Doppler spectra of mitral inflow from a WT-control mouse, a KO-control mouse, a WT-MI mouse, a KO-MI mouse, a WT-MI mouse treated with ACEl, and a KO-MI mouse treated with ACEI. The mitral inflow pattern from the WT-MI mice and KO-MI mice shows an increased peak velocity of the early rapid filling wave (E wave), a rapid deceleration rate of the early rapid filling wave, and a decreased late filling wave due to atrial contraction (A wave) velocity compared with control mice. ACEl decreased $\mathrm{E}: \mathrm{A}$ ratio in WT-MI and KO-MI mice. increased nitric oxide synthesis or an effect on prostaglandin metabolism. However, further work is needed to elucidate in more detail the mechanisms responsible for the beneficial effects of ACE inhibitors in LV remodelling with ATl KO mice after MI.

ACE inhibition decreased blood pressure in WT-MI mice and prevented myocardial remodelling. On the other hand, ACE inhibition did not change blood pressure in KO-MI mice. However, ACE inhibition prevented the increases of ANP, BNP, and collagen mRNAs. Myocardial remodelling is

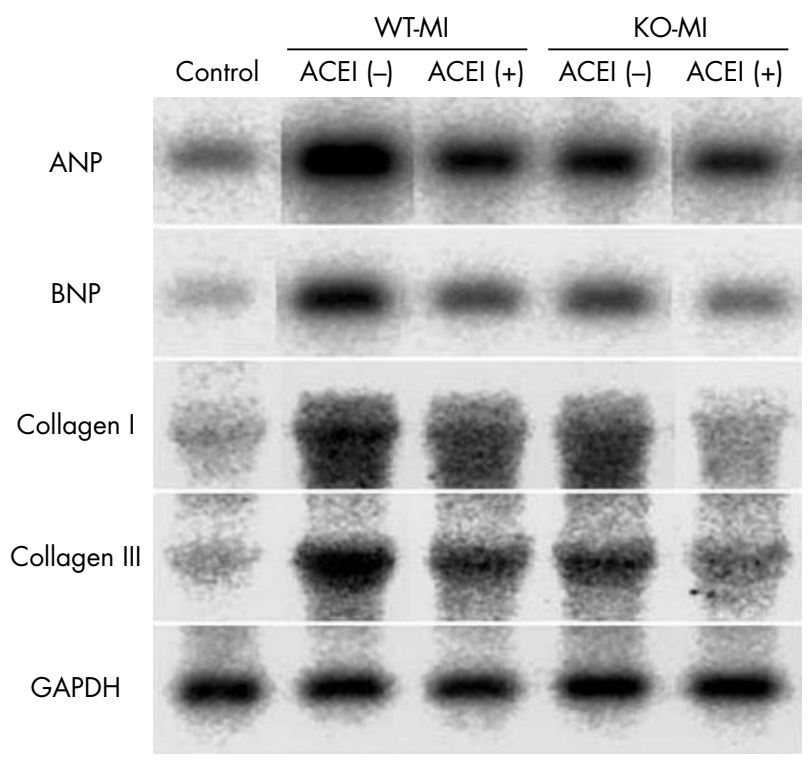

Figure 5 Autoradiograms of northern blot analysis of mRNA expression of atrial natriuretic peptide (ANP), brain natriuretic peptide (BNP), collagens I and III, and glyceraldehyde-3-phosphate dehydrogenase (GAPDH) in the LV non-infarcted region (septum) at four weeks after MI. WT-MI mice and KO-MI mice had increased ANP, BNP, and collagens I and III compared with control mice. ACEI decreased mRNA expression in WT-Ml and KO-MI mice.
Table 3 mRNA expression of ANP, BNP, and collagens I and III in the non-infarcted myocardium after $\mathrm{MI}$

\begin{tabular}{|c|c|c|c|c|}
\hline & \multicolumn{2}{|l|}{ WT-MI } & \multicolumn{2}{|l|}{ KO-MI } \\
\hline & ACEI (-) & ACEI (+) & ACEI (-) & ACEI $(+)$ \\
\hline ANP & $15.0(3.1)$ & $9.6(0.9) \dagger$ & 7.9 (1.9)t† & $3.1(1.1) \dagger \dagger \S$ - \\
\hline BNP & $8.6(0.7)$ & $5.3(0.2)+\dagger$ & $5.9(0.9)+\dagger$ & $2.9(0.2)+\dagger \S \cdot$ \\
\hline Collagen I & $3.9(0.4)$ & $2.7(0.2) \dagger$ & $2.5(0.3) \dagger$ & $1.4(0.2) \dagger+\S$ \\
\hline Collagen III & $4.6(0.5)$ & $3.6(0.1)$ & $3.1(0.4) \dagger$ & $1.9(0.2)+\dagger \S-$ \\
\hline
\end{tabular}

Values are mean (SEM) (control $=1.0 \pm 0.0-0.1$ ).

$\mathrm{ANP}$, atrial natriuretic peptide; BNP, brain natriuretic peptide

$\uparrow p<0.05 v$ WT-MI ACEI (-); ††p $<0.01 v$ WT-MI ACEI $(-) ; \S p<0.05 v$

WT-MI ACEI $(+) ; \S \S p<0.01 \vee$ WT-MI ACEI $(+)$; $9 p<0.05 v$ WT-KO ACEI

$(-) ; \uparrow p<0.01 \vee$ KO-MI ACEI (-).

regulated by mechanical and neurohumoral factors. It is well known that the effect of ACE inhibition on blood pressure is related to myocardial remodelling. Our data suggest that the direct effects of ACE inhibition on the local myocardial renin-angiotensin system may have an important role in preventing myocardial remodelling.

There is a common flaw in any study that uses the knockout model. The gene being knocked out may regulate a multiplicity of processes outside the targeted gene. In this model, chronic hypotension was observed in the heterozygous and homozygous mutant mice compared with WT littermates, and the amounts of renin mRNA in the kidney and plasma renin activity were greatly increased only in the homozygous mutant mice. ${ }^{11}$ The results of this experiment need to be carefully considered in light of non-ATl receptor or other effects. We cannot distinguish between the direct effects of non-ATl receptors on myocardial remodelling and the effects of these receptors on multiple processes outside of the heart and their subsequent indirect effects on myocardial remodelling.

In conclusion, we observed the ability of ACE inhibitors to prevent LV remodelling after experimentally induced MI in ATl KO mice, thereby showing that non-ATl receptor mediated mechanisms have an important role. 


\section{Authors' affiliations}

M Yoshiyama, Y Nakamura, T Omura, R Matsumoto, S Oda,

K Takeuchi, J Yoshikawa, Department of Internal Medicine and Cardiology, Graduate School of Medicine, Osaka City University,

Osaka, Japan

Y Izumi, S Kim, H Iwao, Department of Pharmacology, Graduate School of Medicine, Osaka City University

\section{REFERENCES}

1 Liu YH, Yang XP, Sharov VG, et al. Effects of angiotensin-converting enzyme inhibitors and angiotensin II type 1 receptor antagonists in rats with heart failure: role of kinins and angiotensin II type 2 receptors. J Clin Invest 1997:99:1926-35.

2 Pitt B, Poole-Wilson PA, Segal R, et al. Effect of losartan compared with captopril on mortality in patients with symptomatic heart failure: randomised trial: the losartan heart failure survival study ELITE II. Lancet 2000;355: 1582-7.

3 Yoshiyama M, Takeuchi K, Omura T, et al. Effects of candesartan and cilazapril on rats with myocardial infarction assessed by echocardiography. Hypertension 1999;33:961-8.

4 Urata H, Healy B, Stewart RW, et al. Angiotensin II-forming pathways in normal and failing human hearts. Circ Res 1990;66:883-90.

5 Linz W, Wiemer G, Gohlke P, et al. Contribution of kinins to the cardiovascular actions of angiotensin- converting enzyme inhibitors. Pharmacol Rev 1995;47:25-49.

6 McDonald KM, Mock J, D'Aloia A, et al. Bradykinin antagonism inhibits the antigrowth effect of converting enzyme inhibition in the dog myocardium after discrete transmural myocardial necrosis. Circulation 1995;91:2043-8.

7 Cohn JN, Tognoni G. A randomized trial of the angiotensin-receptor blocker valsartan in chronic heart failure. N Engl J Med 2001;345:1667-75.

8 CHARM-Added Trial Investigators. Effect of candesartan in patients with chronic heart failure and reduced left-ventricular systolic function taking angiotensin-converting-enzyme inhibitors: the CHARM-added trial. Lancet 2003;362:767-71

9 Nakamura Y, Yoshiyama M, Omura T, et al. Beneficial effects of combination of ACE inhibitor and angiotensin II type 1 receptor blocker on cardiac remodeling in rat myocardial infarction. Cardiovasc Res 2003;57:48-54

10 Pfeffer MA, McMurray JJ, Velazquez EJ, et al. Valsartan, captopril, or both in myocardial infarction complicated by heart failure, left ventricular dysfunction, or both. N Engl J Med 2003;349:1893-906.

11 Sugaya T, Nishimatsu S, Tanimoto K, et al. Angiotensin II type la receptordeficient mice with hypotension and hyperreninemia. J Biol Chem 1995;270: 18719-22.

12 Patten RD, Aronovitz MJ, Deras-Mejia L, et al. Ventricular remodeling in a mouse model of myocardial infarction. Am J Physiol 1998;274:H1812-20.
13 Kinugawa S, Tsutsui H, Hayashidani S, et al. Treatment with dimethylthiourea prevents left ventricular remodeling and failure after experimental myocardial infarction in mice: role of oxidative stress. Circ Res 2000;87:392-8.

14 Gay RG. Early and late effects of captopril treatment after large myocardial infarction in rats. J Am Coll Cardiol 1990;16:967-77.

15 Kim S, Ohta K, Hamaguchi A, et al. Angiotensin II induces cardiac phenotypic modulation and remodeling in vivo in rats. Hypertension 1995;25:1252-9.

16 McKay RG, Pfeffer MA, Pasternak RC, et al. Left ventricular remodeling after myocardial infarction: a corollary to infarct expansion. Circulation 1986;74:693-702.

17 Weisman HF, Bush DE, Mannisi JA, et al. Global cardiac remodeling after acute myocardial infarction: a study in the rat model. J Am Coll Cardiol 1985;5:1355-62.

18 Pfeffer JM, Fischer TA, Pfeffer MA. Angiotensin-converting enzyme inhibition and ventricular remodeling after myocardial infarction. Annu Rev Physiol 1995:57:805-26.

19 Pfeffer MA, Braunwald E, Moye LA, et al. Effect of captopril on mortality and morbidity in patients with left ventricular dysfunction after myocardial infarction: results of the survival and ventricular enlargement trial. The SAVE investigators. N Engl J Med 1992;327:669-77.

20 Yamagishi H, Kim S, Nishikimi T, et al. Contribution of cardiac reninangiotensin system to ventricular remodelling in myocardial-infarcted rats. J Mol Cell Cardiol 1993;25:1369-80.

21 Schieffer B, Wirger A, Meybrunn M, et al. Comparative effects of chronic angiotensin-converting enzyme inhibition and angiotensin II type 1 receptor blockade on cardiac remodeling after myocardial infarction in the rat. Circulation 1994;89:2273-82.

22 Nishimura RA, Tajik AJ. Evaluation of diastolic filling of left ventricle in health and disease: Doppler echocardiography is the clinician's Rosetta stone. J Am Coll Cardiol 1997:30:8-18.

23 Yoshibayashi M, Saito Y, Nakao K. Brain natriuretic peptide versus atrial natriuretic peptide: physiological and pathophysiological significance in children and adults: a review. Eur J Endocrinol 1996;135:265-8.

24 Luchner A, Muders F, Dietl O, et al. Differential expression of cardiac ANP and $\mathrm{BNP}$ in a rabbit model of progressive left ventricular dysfunction. Cardiovasc Res 2001;51:601-7.

25 Liu YH, Yang XP, Mehta D, et al. Role of kinins in chronic heart failure and in the therapeutic effect of ACE inhibitors in kininogen-deficient rats. Am J Physiol Heart Circ Physiol 2000;278:H507-14.

26 Yang XP, Liu YH, Mehta D, et al. Diminished cardioprotective response to inhibition of angiotensin-converting enzyme and angiotensin II type 1 receptor in $\mathrm{B}(2)$ kinin receptor gene knockout mice. Circ Res 2001;88:1072-9.

27 Agata J, Chao L, Chao J. Kallikrein gene delivery improves cardiac reserve and attenuates remodeling after myocardial infarction. Hypertension 2002;40:653-9.

\section{STAMPS IN CARDIOLOGY}

\section{Poster stamps}

$P$ oster stamps were an extremely popular advertising medium until approximately the middle of the $20^{\text {th }}$ century. Attached to the envelope in addition to the normal current postage stamp of the time they would serve all the same purposes as a specially designed commemorative postage stamp-advertising and promoting specific events. Some of the most common themes appearing on poster stamps were expositions and sporting events-particularly the Olympic games. Germany was one of the most prolific producers due to the lead held in printing technologies during these times. The poster stamp illustrated was issued to promote the German Health Exhibition in 1914 and depicts a stylised heart and systemic and pulmonary circulations. Due to their vivid designs and colours poster stamps were once very popular collectible items and nowadays, to a large extent, replaced by true stamps in the form of commemorative issues.

M K Davies A Hollman

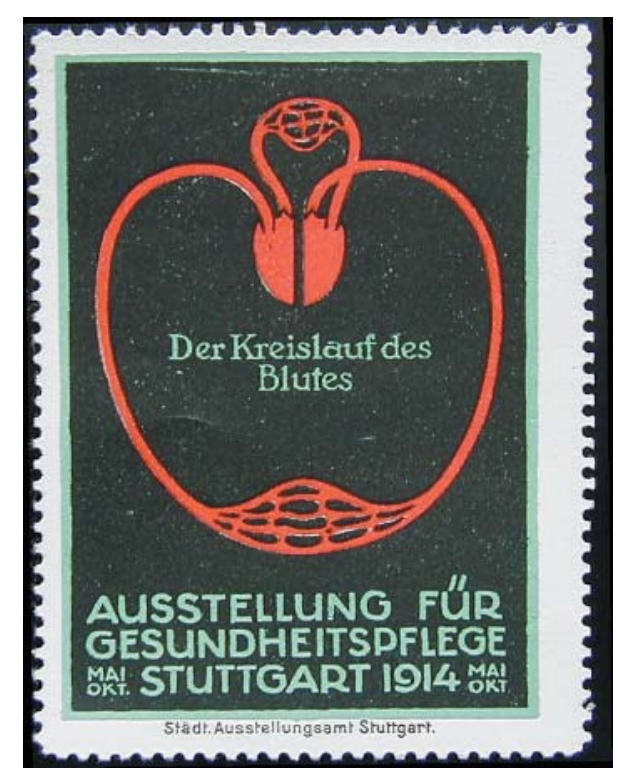

